Chapter 25

\title{
Integrins in Prostate Cancer Invasion and Metastasis
}

\author{
Paulynn Chin Suyin, Joanne Louise Dickinson and \\ Adele Frances Holloway
}

Additional information is available at the end of the chapter

http://dx.doi.org/10.5772/53482

\section{Introduction}

Prostate cancer is the most commonly diagnosed cancer in men and is the second leading cause of cancer deaths in men after non-melanoma skin cancer. According to the United States National Cancer Institute, it was estimated that almost 241740 men would be diagnosed with prostate cancer in the United States alone in 2012 and more than 28170 would die of prostate cancer. Despite considerable advances in prostate cancer research, this cancer is still associated with significant mortality and morbidity [1]. The risk factors involved in the development of prostate cancer include advancing age, race and family history. If detected in the early stage of disease, prostate cancer is considered curable by surgical excision methods, radiotherapy and androgen deprivation therapy [2]. However, in a percentage of men disease recurs, is frequently refractory to treatment and this is associated with poor prognosis. It is thought there is a population of prostate tumour cells that have the capacity to invade and metastasize, with bone being the most common metastatic site. Autopsy studies have found that more than $80 \%$ of men who die of prostate cancer have metastatic boney lesions [3].

The current prostate specific antigen (PSA) screening tool has allowed early detection of prostate cancer, when still locally confined. PSA is a protein produced by the cells in the prostate gland. The PSA screening tool measures the level of PSA in the blood where a high PSA level is indicative of the presence of cancer. However, benign conditions may also show elevated levels of PSA. Therefore, the PSA screening tool has significant limitations resulting in false positives. Further, it is unable to distinguish the aggressive tumours requiring immediate intervention from those that are more appropriately managed by regular surveillance. Thus, there is considerable interest in identifying and discovering new prognostic and 
diagnostic markers for prostate cancer, particularly markers that can identify those tumours likely to progress to a more aggressive state.

Prostatic intraepithelial neoplasia (PIN), in particular high-grade PIN have been identified as precursors to prostate cancer. High-grade PIN is an abnormal condition of the prostate gland and is considered a pre-malignant condition. Studies have reported that approximately $30 \%$ of men with high-grade PIN lesions will develop prostate cancer [4]. Atypical small acinar proliferation (ASAP) is also a precursor to prostate cancer. ASAP lesions mimic cancer and have been found to be strongly predictive of subsequent prostate cancer, with approximately $60 \%$ of men with ASAP found to subsequently develop prostate cancer [5]. The progression of prostate cancer may be driven by the accumulation of genetic and epigenetic changes, leading to the activation of oncogenes and inactivation of tumour suppressor genes [6]. These changes lead to the development of PIN and ASAP which may progress into localised invasive cancer and finally metastatic tumours.

Metastasis is a multistep event and it arises when there is a loss of tumour cell adhesion to the primary site leading to cell detachment. These cells then invade through the extracellular matrix (ECM) and subsequently adhere to secondary sites. The transition from a normal prostate gland to the formation of PIN and to invasive and metastatic cancers involves alterations in the cell surface adhesive receptors, integrins. Integrins play important roles in normal prostate development where they are involved in the interaction of the prostate epithelial cells with the ECM and also influence cell signalling, growth, survival and differentiation. During metastasis, changes in integrin expression results in changes in the tumour cell adhesion to adjacent cells and to the ECM leading to increased cell motility. Thus, integrins are key players in metastatic events since they mediate cell to cell (homotypic) and cell to ECM (heterotypic) interactions of prostate cells.

\section{Integrins}

Integrins belong to a superfamily of transmembrane glycoprotein receptors involved in mediating cell to cell and cell to ECM interactions. They exist as heterodimers composed of $\alpha$ and $\beta$ subunits bound by non-covalent bonds. To date, $18 \alpha$ subunits and $8 \beta$ subunits have been identified, which can associate to form 24 unique complexes (Table 1) with the different $\alpha \beta$ combinations possessing distinct ligand binding specificities [7,8]. There are three distinct regions in each integrin subunit with each subunit containing an extracellular domain, a transmembrane domain and a short intracellular domain.

The extracellular regions of the $\alpha$ and $\beta$ subunits together form the ligand binding site. The most common ligands for integrins are large ECM proteins such as laminin, fibronectin, collagen and vitronectin. These ECM proteins (except for laminin and collagen) have a common arginine-glycine-aspartic acid (RGD) motif, whereas integrins recognise laminin and collagen through cryptic RGD sites. In addition, there are some integrins that interact with other adhesion molecules such as cadherins, intracellular adhesion molecules (ICAMs) and vascular adhesion molecules (VCAMs), expressed on leukocytes and endothelial cells. By 
grouping the integrins according to integrin ligand specificity, the collagen binding integrins are $\alpha 1 \beta 1, \alpha 2 \beta 1, \alpha 3 \beta 1, \alpha 10 \beta 1, \alpha 11 \beta 1$ and $\alpha 6 \beta 4$, the laminin binding integrins are $\alpha 1 \beta 1$, $\alpha 2 \beta 1, \alpha 3 \beta 1, \alpha 6 \beta 1, \alpha 7 \beta 1$ and $\alpha 6 \beta 4$ and the RGD recognising integrins are $\alpha 5 \beta 1, \alpha v \beta 1, \alpha v \beta 3$, $\alpha \mathrm{v} \beta 5, \alpha \mathrm{v} \beta 6, \alpha \mathrm{v} \beta 8$ and $\alpha_{\mathrm{IIb}} \beta 3$. However, integrins can frequently bind several ligands (as outlined in Table 1), permitting redundancy in signalling as multiple integrins are generally present on any particular cell surface.

\begin{tabular}{|c|c|c|}
\hline Integrin & Ligand & \\
\hline$\alpha 1 \beta 1$ & Collagen IV and VI, Laminin-1 & \multirow{4}{*}{ Collagen binding } \\
\hline$a 2 \beta 1$ & Collagen I, Laminin-1,-2 and -10 & \\
\hline$a 10 \beta 1$ & Collagen IV and VI & \\
\hline$\alpha 11 \beta 1$ & Collagen I & \\
\hline$\alpha 3 \beta 1$ & Laminin-5, Collagen IV, Fibronectin & \multirow{4}{*}{ Laminin binding } \\
\hline$a 6 \beta 1$ & Laminin-1, Merosis, Kalinin & \\
\hline$\alpha 7 \beta 1$ & Laminin-1 and -2 & \\
\hline$a 6 \beta 4$ & Laminin- $1,-2,-5$ and -10 & \\
\hline$a 4 \beta 1$ & Fibronectin, VCAM & \multirow{10}{*}{ RGD motif binding } \\
\hline$a 5 \beta 1$ & Fibronectin & \\
\hline$a 8 \beta 1$ & Fibronectin & \\
\hline$\alpha 9 \beta 1$ & Fibronectin, Tenascin, Laminin-1 & \\
\hline$a v \beta 1$ & Fibronectin, Vitronectin & \\
\hline $\operatorname{av\beta 3}$ & Fibronectin, Vitronectin & \\
\hline $\operatorname{av\beta 5}$ & Vitronectin & \\
\hline $\operatorname{av\beta 6}$ & Fibronectin & \\
\hline $\operatorname{av} \beta 8$ & Fibronectin, Collagen IV, Laminin-5 & \\
\hline$a_{\| 1} \beta 3$ & Fibronectin, Vitronectin & \\
\hline$a 4 \beta 7$ & Fibronectin, VCAM & \multirow{6}{*}{ Leukocyte binding } \\
\hline $\mathrm{aE} \beta 7$ & E-cadherin & \\
\hline$a D \beta 7$ & ICAM3, VCAM & \\
\hline $\operatorname{aL} \beta 2$ & ICAM1-5 & \\
\hline $\mathrm{aM} \beta 2$ & ICAM1, VCAM, fibrinogen & \\
\hline$a \times \beta 2$ & Fibrinogen & \\
\hline
\end{tabular}

Table 1. List of integrins and their ligands

As an integrin binds to its ligand, it undergoes structural changes which affect the ligand binding affinity [9]. This affinity is also determined by the cytoplasmic signals from within the cell which affects the molecular interactions at the integrin cytoplasmic domain influencing the degree of cell adhesion. This is refered to as inside-out signaling. Integrins also play a role in signal transduction where they transduce extracellular signals to the interior of the cell, refered to as outside-in signaling. Such signalling can affect cell migration, differentiation, survival and proliferation [10-12]. When bound to the ECM proteins, integrins recruit a 
range of adaptor proteins, and activate various signalling pathways. For example, integrin clustering activates the focal adhesion kinases (FAK), Src family kinases, Rac and Rho GTPases leading to the recruitment of cytoskeleton proteins such as talin, $\alpha$-actinin, vinculin, paxillin and tensin [13]. Activation of these kinase pathways and cytoskeleton proteins contributes to changes in cell architecture, adhesion and migration on the ECM [14].

\section{Roles of integrins in cancer progression}

While integrins mediate cell attachment, ligation of integrins by the ECM proteins induces cell migration by generating the traction required for invasion. In cancer, expression of integrins that are involved in cell adhesion are frequently altered, leading to cell proliferation, migration and metastasis. Previous studies in which integrin expression levels were correlated to the different stages of human tumours and the pathological outcomes (metastasis, recurrence, survival), implicated a number of integrins in cancer progression [15-25]. These integrins include $\alpha v \beta 3, \alpha 2 \beta 1, \alpha 3 \beta 1$ and $\alpha 6 \beta 1$. In contrast integrin $\alpha 4 \beta 1$ is associated with tumour suppression [26].

Integrin $\alpha \mathrm{v} \beta 3$ has been associated with tumour progression in a range of cancers including lung cancer, gastric cancer, breast cancer and prostate cancer [15-18]. Integrin $\alpha v \beta 3$ remains the most well-studied integrin involved in tumour progression. Interestingly, integrin $\alpha \mathrm{v} \beta 3$ is usually only expressed in activated leukocytes, macrophages, platelets and osteoclasts and not normally expressed in epithelial cells. It has been found to mediate adhesion of breast cancer cells to bone matrix and also facilitate migration of breast cancer cells in bone sialoprotein $[19,27]$. In colon cancer, blocking integrin $\alpha v \beta 3$ resulted in a decrease in tumour metastasis and improved survival in mice [21]. This integrin was also found to bind to periostin, which is upregulated in epithelial ovarian cancer cells, and promotes cell adhesion and migration [22].

Changes in integrin $\alpha 2 \beta 1$ have also been associated with tumour progression with loss of integrin $\alpha 2 \beta 1$ resulting in the induction of breast cancer cell metastasis in vivo, suggesting that integrin $\alpha 2 \beta 1$ is a metastasis suppressor [23]. The re-expression of $\alpha 2 \beta 1$ in breast cancer cells reversed some of the tumourigenic properties of the cells [24]. In contrast, in prostate cancer, integrin $\alpha 2 \beta 1$ was found to induce prostate cancer cell metastasis to the bone [25]. Thus, this suggests that integrin function is cell type and context dependent. This was evident in a study by Zhang et al., where integrin $\alpha 2$ knockout mice, when challenged with B16F10 melanoma cells showed increased tumour angiogenesis correlating with increased vascular endothelial growth factor receptor 1 (VEGFR-1) [28]. However, the $\alpha 2$ knockout mice bearing Lewis Lung carcinoma (LLC) cells showed no difference in tumour angiogenesis. Further analysis showed that the integrin $\alpha 2 \beta 1$-dependent angiogenesis involves the secretion of placental growth factor (PLGF) which was produced by B16F10 cells but not the LLC cells. These data suggest that integrin expression is cell type and context dependent where it is dependent on the interactions of the host factors with the surrounding microenvironment. 


\section{Roles of integrins in prostate cancer progression}

Integrins are expressed in normal prostate basal cells and are required for the interaction of the cells with surrounding stroma which influences their growth, survival and differentiation potential. These integrins include $\alpha 2 \beta 1, \alpha 3 \beta 1, \alpha 5 \beta 1$ and $\alpha 6 \beta 4$ [29-33]. Altered expression of integrins affects cell adhesion to adjacent cells and to the ECM and such affects have been observed in solid tumours and prostate cancer cell lines. Table 2 highlights the most well characterised integrins involved in prostate cancer progression, migration and invasion, and these integrins are discussed below.

Bonkhoff et al. (1993) investigated the expression of integrin $\alpha 2 \beta 1$ in normal, hyperplastic and neoplastic human prostate tissue as well as lymph node metastases samples. Results showed downregulated $\alpha 2 \beta 1$ in $70 \%$ of the hyperplastic samples compared to normal prostate tissues. However, $\alpha 2 \beta 1$ was upregulated in the lymph node metastases compared to primary lesions. In another study, the role of integrin $\alpha 2$ in prostate cancer metastasis was investigated [34]. Immunofluorescence staining showed the presence of $\alpha 2$ and $\beta 1$ subunit clusters in bone metastatic prostate cancer cells (C4-2B) and not in the lymph node metastatic prostate cancer cells (LNCaP), in contrast to the findings of Bonkhoff et al. which reported $\alpha 2 \beta 1$ upregulation in lymph node metastasis. The functional blocking of the integrin $\alpha 2$ subunit with antibodies in the C4-2B bone metastatic prostate cancer cell line resulted in reduced adhesion and inhibiton of invasion to collagen I [34]. The role of $\alpha 2 \beta 1$ in bone metastasis is further supported by a study by Hall et al. (2006). A collagen-binding LNCaP cell line was derived (LNCaPcol) and showed increased levels of $\alpha 2 \beta 1$ with associated increased migration towards collagen I [35]. In an in vivo analysis of these cells, in which LNCaPcol was injected into the tibia of nude mice, the LNCaPcol injected mice developed bone tumours. A follow-on study was conducted to investigate the signalling pathways involved in $\alpha 2 \beta 1$ stimulated migration [25]. RhoC guanosine triphosphatase activity was increased by five to eight fold in collagen binding cell lines, CB-2B and LNCaPcol compared to non-collagen binding LNCaP. These results support the idea that ligation of collagen I to $\alpha 2 \beta 1$ activates the RhoC signalling pathway, which mediates prostate cancer invasion and metastasis to the bone.

A microarray study was conducted on 111 individuals with localised prostate cancer who had undergone radical prostectomy, including 60 individuals who had tumour recurrence after a follow-up of 123 months [36]. In this study increased integrin $\alpha 3$ and $\alpha 3 \beta 1$ expression were found to be related to worse outcome with strong $\alpha 3$ and $\alpha 3 \beta 1$ expression associated with higher incidence of recurrence. In another microarray study performed on five prostate cancer cell lines (LNCaP, DU145, PC3, LAPC-4 and 22Rv1) and 13 prostate cancer xenografts, integrin $\alpha 4$ showed decreased expression associated with deletion of the integrin $\alpha 4$ locus [26]. Since all samples were derived from metastases, it suggests that integrin $\alpha 4$ could be a tumour suppressor. Interestingly, integrin $\alpha 7$ has also been identified as a tumour suppressor [13]. The prostate cancer cell lines, PC3 and DU145 were transfected with integrin $\alpha 7$ expression vector and implanted in SCID mice. After six weeks, the volume of the tumours were measured and compared to mice transfected with control vector. Results showed re- 
duced tumour volume and fewer metastases in the integrin $\alpha 7$ vector transfected mice. Further analysis of metastasic potential using a wound-healing assay showed reduced rates of migration in both PC3 and DU145 cells overexpressing integrin $\alpha 7$. Thus, these studies support the notion that integrin $\alpha 7$ inhibits cell migration and acts as a tumour suppressor.

An early study using DU145 and PC3 cells, which express integrin $\alpha_{\mathrm{IIb}} \beta 3$, suggested that integrin $\alpha_{\mathrm{II}} \beta 3$ is also involved in prostate cancer metastasis [37]. Although both cell lines express integrin $\alpha_{\mathrm{II}} \beta 3$, immunofluorescence data showed different localisation patterns of the integrin. In DU145 cells the integrin localizes to focal contact sites whereas in PC3 cells, it is mainly intracellular. Interestingly, when both the tumourigenic cell lines were injected intraprostatically into SCID mice, only the DU145 cells metastasized. Further analysis by flow cytometry with an antibody to $\alpha_{\mathrm{II}} \beta 3$ showed higher expression of $\alpha_{\mathrm{IIb}} \beta 3$ in DU145 cells isolated from the prostate when compared to DU145 cells from the subcutaneous tissue. Therefore, the data suggests that integrin $\alpha_{\mathrm{IIb}} \beta 3$ is involved in the metastatic progression of prostate tumours. Recently, integrin $\alpha 5 \beta 1$ also has been found to be important in cell adhesion in prostate cancer cells [38]. When integrin $\alpha 5 \beta 1$ was blocked with an antibody, a decrease in the number of adherent PC3 cells to fibronectin was observed. Partial inhibition of the PC3 cell migration and the formation of quasi-spherical cell shape changes were observed, suggesting a reversal to a less mesenchymal phenotype. In addition, the blocking of $\alpha 5 \beta 1$ resulted in weak expression of the cytoskeletal proteins F-actin and $\alpha$-actinin suggesting a weak cell-fibronectin interaction. Thus, these results support the idea that integrin $\alpha 5 \beta 1$ plays an important role in the adhesion of PC3 cells to fibronectin and the migration of PC3 cells.

Integrin $\alpha \mathrm{v} \beta 3$ has also been identified to be involved in prostate cancer metastasis. Zheng et al. (1999), found expression of integrin $\alpha v \beta 3$ in 16 prostate cancer specimens but not in normal prostate epithelial cells. The highly metastatic and invasive PC3 cell line also expresses integrin $\alpha v \beta 3$ but not the non-invasive LNCaP cell line [39]. These $\alpha v \beta 3$ expressing PC3 cells and the primary prostate cancer cells were found to adhere and migrate on vitronectin. When LNCaP cells were transfected with a $\alpha v \beta 3$ expression plasmid to induce $\alpha v \beta 3$ expression, LNCaP cells also adhered to and migrated on vitronectin. Thus, this study suggests that $\alpha v \beta 3$ is potentially involved in prostate cancer invasion and metastasis. A following study found integrin $\alpha \mathrm{v} \beta 3$ to be involved in bone metabolism and angiogenesis [40]. To investigate how inhibition of integrin $\alpha \mathrm{v} \beta 3$ in cells native to the bone would affect prostate cancer bone metastasis, a prostate cancer cell line that expresses little or no integrin $\alpha \mathrm{v} \beta 3$ was chosen. Interestingly, in this study, PC3 cells were used as they found undetectable levels of $\alpha v \beta 3$ by FACS analysis and by using antibody staining. This is conflicting with the previous study which reported expression of $\alpha v \beta 3$ in PC3 cells and it is possible that this is due to the use of different types of antibodies. Regardless, PC3 cells were injected directly into human bone fragments which were previously implanted subcutaneously in SCID mice and the mice were treated with anti- $\beta 3$ antibody fragment $\left(\mathrm{m} 7 \mathrm{E} 3 \mathrm{~F}\left(\mathrm{ab}^{\prime}\right)_{2}\right)$. This antibody only blocks the human bone-derived $\alpha v \beta 3$. After two weeks of treatment, inhibition of integrin $\alpha v \beta 3$ resulted in a reduced proportion of antigenically-human blood vessels within tumourbearing bone implants. In addition, a reduction in the rate of tumour cell proliferation with- 
in the bone implants, reduced osteoclast number and degradation of calcified bone tissue were observed.

The integrin $\alpha 6$ can pair with either $\beta 1$ or $\beta 4$ subunits and it binds to laminin. The integrin $\alpha 6 \beta 4$ is a laminin receptor and is known as a hemidesmosome complex, mediating cell attachment to the ECM. It acts as the junctional complex on the basal cell surface and is involved in the attachment of epithelial cells to the adjacent basement membrane. In contrast, integrin $\alpha 6 \beta 1$ has been found to be involved in the cell migratory phenotype. The expression and distribution of integrin $\alpha 6 \beta 1$ in normal, hyperplastic and neoplastic prostate tissue and lymph node metastases was examined [33]. Approximately $85 \%$ of the grade I and grade II tumours and also the lymph node metastases showed upregulation of integrin $\alpha 6 \beta 1$, compared to normal and hyperplastic samples. Staining showed clusters of $\alpha 6 \beta 1$ receptors in acinar basement membranes which suggests integrin $\alpha 6 \beta 1$ is important in mediating cell attachment to the basement membrane. Then, Nagle et al. (1994), found that while most of the prostate carcinoma tissues they tested displayed downregulation of integrins, the majority of these samples expressed $\alpha 6 \beta 1$ [41]. This is consistent with the loss of integrin $\beta 4$ in the carcinoma samples. In a separate study, integrin $\beta 4$ was found to be absent in prostate carcinoma tissues and only present in normal prostate glands and PIN lesions [42], supporting the previous study. Therefore, these data suggest that integrin $\beta 4$ is lost during cancer progression and therefore, integrin $\alpha 6$ is preferentially paired with the $\beta 1$ subunit, forming $\alpha 6 \beta 1$. A following study found a variant form of integrin $\alpha 6, \alpha 6 \mathrm{p}$ which was expressed in DU145, LNCaP and PC3 prostate cancer cell lines but not expressed in the normal prostate cells, PrEC [32]. This $\alpha 6 \mathrm{p}$ variant also binds to both the $\beta 1$ and the $\beta 4$ subunits and has three times longer half-life than $\alpha 6$. Recently, King et al. (2008) investigated the role of integrin $\alpha 6 \beta 1$ in prostate cancer migration and bone pain in a novel xenograft mouse model [43]. The human prostate cancer cells (PC3N), were stably transfected to overexpress either the cleavable wild type (PC3N- $\alpha 6-\mathrm{WT}$ ) which forms the $\alpha 6 \mathrm{p}$ variant or the uncleavable (PC3N- $\alpha 6-\mathrm{RR}$ ) form of integrin $\alpha 6$. The $\alpha 6$ subunit can be cleaved via Urokinase-type Plasminogen Activator (uPA) treatment and the cells were directly injected and sealed into the femur of a mouse. After 21 days, tumour cells expressing wild-type integrin $\alpha 6$ (non-cleavable) showed a significant decrease in bone loss, unicortical or bicortical fractures and decreased ability of tumour cells to reach the epiphyseal plate of bone and prevented movement evoked pain, compared to the cleavable a6 integrin. Thus, these results suggest that blocking of integrin $\alpha 6$ cleavage in prostate tumour cells results in decreased tumour cell migration within the bone and reduced bone fractures and pain.

\section{Epithelial-mesenchymal transition}

Epithelial cell structure is maintained by cell-cell interactions involving tight junctions and desmosomes and these cells are non-motile. In contrast, mesenchymal cells do not have cellcell contacts but have distinct cell-ECM interactions and cytoskeletal structures and are motile. Epithelial-mesenchymal transition (EMT) is a series of events where the cell-cell and cell-ECM interactions are altered resulting in detachment of epithelial cells from the sur- 
rounding tissue followed by rearrangement of the cytoskeleton to confer the ability to move through a three-dimensional ECM and the induction of a series of new transcriptional signaling pathways to maintain the mesenchymal phenotype [42]. This process is important in embryonic development, particularly in gastrulation and segment formation. However, more recently, EMT has been implicated in carcinogenesis. EMT involves a multistep process in which the non-motile epithelial cells are tranformed into motile invasive cells [43]. This process is quite similar to the onset of the invasive metastasis process where there is a transition from a benign to aggressive tumour phenotype, involving the detachment of tumour cells from the primary site followed by invasion through the ECM (Figure 1). The reverse of the EMT process is known as mesenchymal-epithelial transition (MET), which facilitates tumour cell attachment at secondary sites.

\begin{tabular}{|c|c|c|}
\hline Integrin & Integrin expression & Reference \\
\hline \multirow{3}{*}{$\alpha 2 \beta 1$} & $\downarrow$ Prostate hyperplastic tissue & Bonkhoff et al. (1993) \\
\hline & $\uparrow$ Metastatic prostate cancer tissue & Hall et al. (2006), Bostwick DG et al. \\
\hline & $\uparrow$ Metastatic prostate cancer cell lines & $(2006)$ \\
\hline$\alpha 3 \beta 1$ & $\uparrow$ Associated with higher recurrence & Pontes-Junior et al. (2010), \\
\hline$a_{\| b} \beta 3$ & $\uparrow$ Metastatic prostate cell lines & Trikha et al. (1998) \\
\hline a4 & $\begin{array}{l}\downarrow \text { Metastatic prostate cencer cell lines and xenograft } \\
\text { samples }\end{array}$ & Saramaki et al. (2006) \\
\hline a7 & $\downarrow$ Metastatic xenograft samples & Ren et al. (2007) \\
\hline $\operatorname{av\beta 3}$ & $\begin{array}{l}\uparrow \text { Prostate cancer tissue samples, metastatic prostate } \\
\text { cancer cell lines }\end{array}$ & $\begin{array}{l}\text { Zheng et al. (1999), Nameth et al. } \\
\qquad \text { (2003) }\end{array}$ \\
\hline$a 5 \beta 1$ & $\uparrow$ Metastatic prostate cancer cell line & Stachrurska et al. (2012) \\
\hline$a 6 \beta 1$ & $\begin{array}{c}\uparrow \text { Metastatic prostate cancer tissue and metastatic } \\
\text { prostate cancer cell lines }\end{array}$ & $\begin{array}{c}\text { Davis et al. (2001), Bonkhoff et al. } \\
\text { (1993), Trikha et al. (1998), King et al. } \\
\text { (2008) }\end{array}$ \\
\hline a6ß4 & $\downarrow$ Metastatic prostate cancer tissue & Davis et al. (2001) \\
\hline
\end{tabular}

Table 2. Integrin expression in prostate cancer progression

EMT involves a series of signalling processes. Firstly, it involves the break-down of cell-cell interactions leading to loss of E-cadherin expression and the upregulation of mesenchymal markers such as N-cadherin, vimentin and the transcription factors Snail, TWIST and ZEB family members. Then, it is followed by a loss of cell polarisation and cytoskeleton remodelling. Finally, changes in cell adhesion occur leading to cell detachment and the activation of proteolytic enzymes; matrix metalloproteinases (MMPs) [44]. The initiation of EMT is tissue and context dependent and may not involve all EMT markers [45]. There are various stimuli from outside the cell which regulate EMT within the tumour microenvironment. These include the binding of transforming growth factor- $\beta$ (TGF $\beta$ ) to the TGF $\beta$ receptor (TGF $\beta r$ ), 
growth factors such as epidermal growth factor (EGF), fibroblast growth factor (FGF) and hepatocyte growth factor (HGF) which bind to the tyrosine-kinase receptor (TKR), the highly conserved $\mathrm{Wnt} / \beta$-catenin pathway and also integrin signalling which activates the FAK signalling pathway $[46,47]$. Since integrins are involved in cell adhesion and signalling, it is possible that integrins can initiate and mediate EMT and invasion in tumour progression (Figure 1).

E-cadherin is a type-I cell-cell adhesion glycoprotein and is a major inducer of EMT as loss of E-cadherin results in decreased cell adhesion and thus, increased cell motility. It is expressed by most epithelial tissues and it forms the tight junction connecting adjacent cells and thus, the formation of stable cell-cell contact. Loss of E-cadherin has been associated with tumour progression and metastasis in breast cancer, prostate cancer, colorectal cancer and gastric cancer [44-48]. Besides genetic and epigenetic factors, transcription factors such as the zinc finger proteins, Snail, Slug, ZEB1, ZEB2 and the basic helix-loop-helix protein, TWIST are involved in the repression of E-cadherin. The zinc finger proteins repress E-cadherin by binding to the E-box motif in the E-cadherin promoter. The role of the Snail transcription factor on E-cadherin has been studied in epithelial tumour cell lines of different origins including bladder cancer, pancreatic cancer and colon cancer. Most of the cell lines showed an inverse correlation between E-cadherin and Snail expression levels and when Snail was transfected into the cell lines that express high E-cadherin levels, it resulted in down-regulation of E-cadherin [49]. It has been proposed that Snail and ZEB2 initiate the silencing of E-cadherin by modifying chromatin organisation of the gene [50]. Subsequently, Slug and ZEB1 have been proposed to be responsible for maintaining the repression of Ecadherin and thus, maintenance of the mesenchymal phenotype [51].

TGF $\beta$ signaling is the main inducer of EMT in the development of cancer. Interestingly however, the TGF $\beta$ response is context-dependent where it can either act as a growth inhibitor or it can induce tumour progression by promoting angiogenesis, immune suppression and preventing apoptosis $[52,53]$. The main role of TGF $\beta$ is to induce apoptosis and thus, it generally acts as a tumour suppressor during the early stages of cancer progression. However, frequent loss-of-function mutations in TGF $\beta$ have been observed in cancer, which is associated with the progression of cancer by inducing cell metastasis. Multiple signalling pathways are involved in the induction of EMT by TGF $\beta$ including the Wnt/ $\beta$-catenin pathway and integrin signalling pathways. Ligation of the TGF $\beta r$ results in the activation of Smad2 and Smad3 and constitutive phosphorylation of Smad4 [54]. These Smads then bind to ZEB1 and ZEB2 to repress E-cadherin expression [55-57]. Miyaki et al. (1999) found increased mutations in Smad 4 as the stage of colorectal tumours advanced, suggesting that inactivation of Smad 4 in the TGF $\beta$ signalling pathway induces tumour metastasis [58].

Activation of the TKR by growth factors has also been found to induce EMT. Stimulation of the breast cancer cell line, PMC42-LA with EGF resulted in E-cadherin downregulation and upregulation of vimentin expression [59]. This is followed by increased cell adhesion and migratory capacity suggesting the upregulation of integrins upon EGF treatment. Integrins have also been linked to EMT as discussed below. 


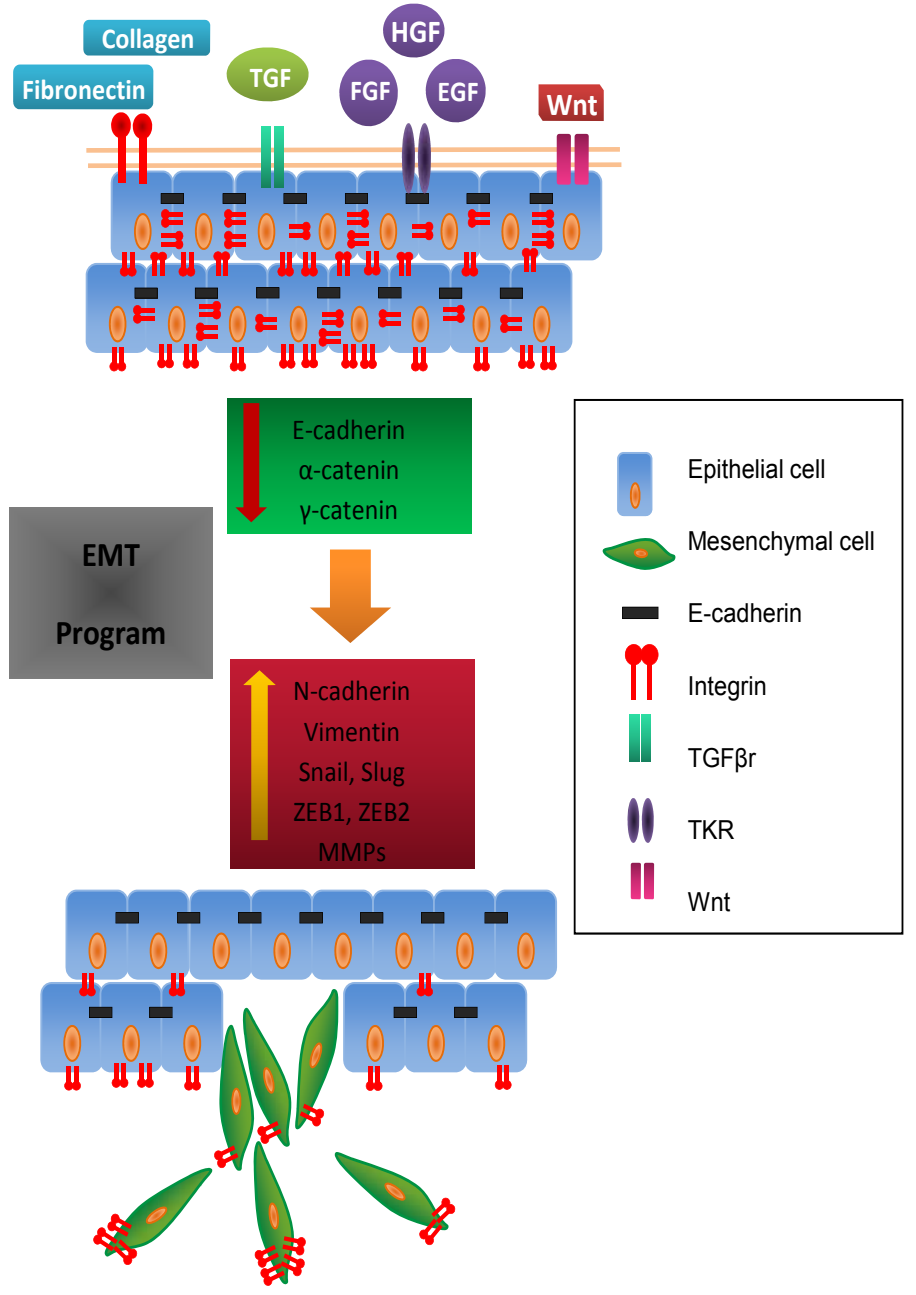

Figure 1. Schematic representation of the EMT process and the roles of integrins in cell adhesion and migration

\section{Roles of integrins and EMT in cancer}

To date, studies on the involvement of integrins in EMT during cancer progression have been limited, particularly in prostate cancer. Here we highlight the recent studies which correlate integrins (implicated in prostate cancer) and EMT. EMT involving changes in the expression of cadherins has been observed in prostate cancer progression [44]. Loss of Ecadherin (epithelial marker) expression has been correlated with increased tumour grade, 
with 46 out of 92 prostate tumour samples showing reduced or absence of E-cadherin staining when compared to non-malignant prostate samples [45]. In contrast N-cadherin (mesenchymal marker), was not expressed in normal prostate tissue but expressed in the poorly differentiated areas of prostate cancer specimens, where E-cadherin was absent [44]. These studies suggest that switching of cadherin expression correlates with prostate cancer metastasis.

Collagen type I which is the ligand of integrin $\alpha 2 \beta 1$ was found to induce the disruption of E-cadherin adhesion complexes in pancreatic cancer [60]. The study suggested that binding of collagen type I to $\alpha 2 \beta 1$ activates FAK phosphorylation which enhances tyrosine phosphorylation of $\beta$-catenin and causes the disassembly of the E-cadherin complex. In addition, Shintani et al. (2008) showed that activation of integrin $\alpha 2 \beta 1$ by collagen type I together with activation of the discoidin domain receptor 1 (DDR1) induces $\mathrm{N}$-cadherin expression [61]. Furthermore, high E-cadherin was observed in suspended PC3 cells and the expression decreased as cells attached to a fibronectin substrate, whereas N-cadherin expression was 4fold lower in suspension cells compared with attached cells [62]. Blocking of the integrin $\beta 1$ by the AIIB2 antibody resulted in no increase of N-cadherin expression in PC3 cells, suggesting that integrin $\beta 1$-mediated cell adhesion to fibronectin is involved in regulating $\mathrm{N}$ cadherin expression in prostate cancer. The study also investigated the regulation of $\mathrm{N}$ cadherin by Twist1 (a transcription factor that regulates mesenchymal gene expression). Knockdown of Twist1 expression in PC3 cells resulted in decreased N-cadherin expression and inhibition of cell migration. Interestingly, blocking of integrin $\beta 1$ correlated with inhibition of nuclear accumulation of Twist1 following cell attachment. Therefore, these data suggest that the integrin $\beta 1$-mediated adhesion is regulated through Twist1 accumulation and activation of $\mathrm{N}$-cadherin.

Integrins have also been shown to activate latent TGF $\beta$. TGF $\beta$ is involved in tissue homeostasis and is both a tumour suppressor and tumour inducer, as outlined above. Tumour cells have increased secretion of TGF $\beta$ which induces EMT [63]. Studies have found that TGF $\beta$ can be activated by integrins. Bates et al. (2005), developed a colon cancer model of EMT, where EMT can be induced in the LIM 1863 colon cancer cell line by exposure to TGF $\beta$. This model showed that EMT resulted in upregulation of integrin $\alpha v \beta 6$. This occurs through the Ets-1 transcription factor and integrin $\alpha v \beta 6$ was found to promote the activation of autocrine TGF $\beta$ in post-EMT to stabilize and sustain EMT and also promote cell migration on fibronectin [64]. In another study, in order to study the role of TGF $\beta$, stable clones of truncated TGF $\beta$ were generated in non-transformed mouse mammary ductal epithelial cells (NmuMG) [65]. The truncated TGF $\beta$ resulted in blocking of TGF $\beta$-mediated growth inhibition, Smad-mediated transcriptional activation, AKT signaling pathways and EMT. However, this did not block the TGF $\beta$-mediated p38MAPK activation. Further, blocking of integrin $\beta 1$ with antibody resulted in inhibition of p38MAPK and EMT progression. Therefore, these results suggest that TGF $\beta$-induced EMT is dependent on both p38MAPK activation and integrin $\beta 1$ which thus suggests the cooperation of TGF $\beta$ and integrins in the modulation of EMT progression. 
The mesenchymal transcription factor Snail plays a role in EMT by repressing E-cadherin. A study investigated the regulation of integrin $\alpha \mathrm{v}$ expression by Snail in epithelial Madin-Darby canine kidney (MDCK) and A431 cells [66]. Upregulation of integrin $\alpha \mathrm{v}$ was observed in MDCK Snail transfected cells and A431 Snail transfected cells. Further investigation showed expression of integrin $\alpha \mathrm{v}$ was mediated directly through its promoter by the Snail transcription factor. In addition, MDCK Snail transfected cells showed increased cell migration towards osteopontin, the ligand for integrin $\alpha v \beta 3$ in bone. Therefore, these data suggest that Snail enhances cell migration, at least in part, by regulating integrin expression in cells. A more recent study which involved stable transfection of Snail into ARCaP and LNCaP prostate cancer cell lines, found a decrease in cell adhesion and increase in cell migration on collagen I and fibronectin [67]. The Snail transfected ARCaP cells were then subjected to flow cytometry and results showed downregulation of integrin $\alpha 5, \alpha 2$ and $\beta 1$, which was reversed by Snail knockdown.

A microarray study undertaken to examine 19 primary prostate tumours showed $65 \%$ loss of E-cadherin in metastatic tumour samples compared to primary tumours [18]. The expression levels also correlated with a $71 \%$ loss of integrin $\beta 4$ when comparing metastatic to primary tumours. These results suggest that progression of prostate cancer involves the loss of E-cadherin and a possible involvement of E-cadherin in regulating integrin $\beta 4$ expression. More recently, a study has found expression of ZEB1 which is a dual zinc finger transcription factor and a known regulator of EMT to repress integrin $\beta 4$ expression in PC3 cells [68]. Further, transient transfection of ZEB2 in the colon cancer cell line, SW480 was found to upregulate the expression of integrin $\alpha 5$ [69]. Knockdown of ZEB2 resulted in suppression of integrin $\alpha 5$ and the cells displayed reduced cell invasion. In addition, ZEB2 was found to cooperate with the SP1 transcription factor to activate the integrin $\alpha 5$ and vimentin promoters and thus, induction of the mesenchymal gene during EMT in cancer progression.

\section{Integrins as therapeutic targets}

As previously discussed, integrins have been shown to mediate tumour progression, tumour cell metastasis and EMT in both in vitro and in vivo models. Thus, these preclinical studies have suggested that integrins could be a novel therapeutic target to prevent cancer progression, including prostate cancer. Currently, studies have been focused on targeting integrin $\alpha v \beta 3$ in breast cancer, ovarian cancer and prostate cancer. Integrin $\alpha v \beta 3$ is likely to be a good cancer angiogenesis target because it is highly expressed on tumour-associated new blood vessels and the surface of most epithelial tumours cells.

There are currently antibody-type inhibitors (LM609, MEDI-522, CNTO95, c7E3, 17E6) or peptide-type inhibitors (Cilengitide, ATN-161) under investigation. However, here only inhibitors that have been tested specifically on prostate cancer models will be reviewed. MEDI-522 is a humanized monoclonal antibody specific for integrin $\alpha v \beta 3$ and a phase I dose escalation trial was conducted in 25 individuals with a variety of metastatic solid tumours which included, breast, colorectal, melanoma, non-small cell lung cancer, ocular mel- 
anoma, renal, sarcoma and prostate cancers [70]. Participants in the trial were treated on a daily basis with dosages ranging from 2 to $10 \mathrm{mg} / \mathrm{kg} / \mathrm{wk}$, intravenously. Treatment showed a possible effect on tumour perfusion with an increase in mean transit time of blood through target tumour lesions after 8 weeks. There were no significant toxicities observed in the treated individuals, with only mild constitutional and gastrointestinal symptoms observed. Only two individuals with metastatic renal cancer remained on treatment and showed prolonged stable disease for 1 or 2 years, respectively, suggesting MEDI-522 may have clinical activity in metastatic renal cancer. Currently, a phase II, randomized, open-label, two-arm, multicenter study of MEDI-522 in combination with docetaxel (an anti-mitotic, standard chemotherapy drug), prednisone (a glucocorticoid prodrug), and zolendronic acid (a bisphosphonate) in individuals with metastatic androgen-independent prostate cancer has just been completed. However, the results of the trial have not been documented yet.

CNTO95 is a fully human antibody that recognizes the integrin $\alpha \mathrm{v}$. It binds to both integrin $\alpha v \beta 3$ and $\alpha v \beta 5$ [71]. CNTO95 was found to inhibit adhesion and migration of HUVECs (human umbilical vein endothelial) and A375.S2 (human melanoma) cells on vitronectin, fibrinogen, gelatin and fibrin, which are ligands for integrin $\alpha v \beta 3$ and $\alpha v \beta 5$. In an in vivo study, CNTO95 inhibited the growth of human melanoma tumours in nude mice by approximately $80 \%$ and reduced final tumour weight by $99 \%$, thus suggesting it has antitumour effects. A phase I clinical study was conducted in 24 individuals with a variety of advanced solid tumours. However, there were no individuals with prostate cancer included in this study. CNTO95, administered intravenously, was generally well tolerated with no adverse side effects. Individuals with ovarian cancer showed a prolonged stable disease with CNTO95 treatment and a 9 month partial response was observed in one individual with angiosarcoma. Interestingly, the partial response was observed in an individual with tumour expressing integrin $\alpha v \beta 1$ and not $\alpha v \beta 3$, suggesting a broad specificity for integrin $\alpha v$. Currently, a phase II study of CNTO95 in combination with docetaxel for the first-line treatment of individuals with metastatic hormone refractory prostate cancer has been completed, although the results have yet to be documented.

Cilengitide is a cyclic peptide that is a potent and selective inhibitor of integrin $\alpha v \beta 3$ and $\alpha v \beta 5$ mediated cell adhesion. In a phase I study, Cilengitide was administrated as a continuous infusion in 4 week cycles at doses of 1, 2, 4, 8, 12, 18, 27, and 40mg/h in 25 individuals with a variety of solid tumours including prostate cancer. This study showed that Cilengitide was generally well tolerated as a continuous infusion and only mild side effects were observed. However, the variable dose did not affect tumour size. This lack of dose-response could be because the lowest dose was as effective as the highest dose. Interestingly, two phase II studies on Cilengitide were conducted by the same research team [72, 73]. In the earlier study, Cilengitide was administrated at $500 \mathrm{mg}$ and $2000 \mathrm{mg}$, intravenously twice weekly in 44 asymptomatic individuals with metastatic castrate resistant prostate cancer (CRPC) [72]. The treatment was randomized and well tolerated and at the endpoint at 6 months, $9 \%$ of participants treated with $500 \mathrm{mg}$ Cilengitide and $23 \%$ of participants treated with 2000 mg Cilengitide showed no tumour progression, suggesting better outcomes with the higher dose. The majority of the participants showed stable disease for 9 months. In the 
second phase II study, Cilengitide was adminitrated at $2000 \mathrm{mg}$, intravenously twice weekly until toxicity or progression in individuals with non-metastatic CRPC [73]. This treatment was well tolerated although two grade three toxicities (atrial fibrillation) were observed. In addition, Cilengitide showed no detectable clinical activity in this study.

\section{Conclusion}

The in vivo, in vitro and clinical studies reviewed here have shown that integrins are a promising therapeutic target in cancer progression and metastasis including prostate cancer. Since integrins are involved in mediating cell adhesion, deregulation of integrins leads to tumour invasion and metastasis. Studies have also found integrins to be involved in EMT in cancer progression. This occurs by either direct activation of the integrin and its signalling pathway or by activating the TGF $\beta$ pathway and also mediating EMT transcription factors. However, studies on the involvement of integrins and the pathways involved in EMT is still very limited. Therefore, further studies are warranted to clarify the processes underlying integrin involvement in EMT in cancer progression. To date, there are still no clinical studies investigating the effect on EMT of integrin inhibitors. These studies will improve our understanding of the integrin mediated EMT pathway and the effects on tumour metastasis. Since bone metastasis is the major cause of prostate cancer related death, targetting integrins using integrin inhibitors could potentially prove valuable in the prevention of the development of prostate cancer boney lesions.

\section{Author details}

Paulynn Chin Suyin, Joanne Louise Dickinson and Adele Frances Holloway

Menzies Research Institute Tasmania, University of Tasmania, Hobart, Tasmania, Australia

\section{References}

[1] Rider. JR, Sandin F, Andren O, Wiklund P, Hugosson J, Stattin P. Long-term Outcomes Among Noncuratively Treated Men According to Prostate Cancer Risk Category in a Nationwide, Population-based Study. European urology. 2012 Aug 10:aheadofprint.

[2] Fleshner NE, Evans A, Chadwick K, Lawrentschuk N, Zlotta A. Clinical significance of the positive surgical margin based upon location, grade, and stage. Urologic oncology. 2010 Mar-Apr;28(2):197-204. 
[3] Bubendorf L, Schopfer A, Wagner U, Sauter G, Moch H, Willi N, et al. Metastatic patterns of prostate cancer: an autopsy study of 1,589 patients. Human pathology. 2000 May;31(5):578-583.

[4] Lefkowitz GK, Taneja SS, Brown J, Melamed J, Lepor H. Followup interval prostate biopsy 3 years after diagnosis of high grade prostatic intraepithelial neoplasia is associated with high likelihood of prostate cancer, independent of change in prostate specific antigen levels. The Journal of urology. 2002 Oct;168(4 Pt 1):1415-1418.

[5] Bostwick DG, Meiers I. Atypical small acinar proliferation in the prostate: clinical significance in 2006. Archives of pathology \& laboratory medicine. 2006 Jul;130(7): 952-957.

[6] De Marzo AM, Platz EA, Sutcliffe S, Xu J, Gronberg H, Drake CG, et al. Inflammation in prostate carcinogenesis. Nature reviews Cancer. 2007 Apr;7(4):256-269.

[7] Hynes RO. Integrins: versatility, modulation, and signaling in cell adhesion. Cell. 1992 Apr 3;69(1):11-25.

[8] Rosales C, O'Brien V, Kornberg L, Juliano R. Signal transduction by cell adhesion receptors. Biochimica et biophysica acta. 1995 Jul 28;1242(1):77-98.

[9] Hughes PE, Renshaw MW, Pfaff M, Forsyth J, Keivens VM, Schwartz MA, et al. Suppression of integrin activation: a novel function of a Ras/Raf-initiated MAP kinase pathway. Cell. 1997 Feb 21;88(4):521-530.

[10] Lee JW, Juliano R. Mitogenic signal transduction by integrin- and growth factor receptor-mediated pathways. Molecules and cells. 2004 Apr 30;17(2):188-202.

[11] Hood JD, Cheresh DA. Role of integrins in cell invasion and migration. Nature reviews Cancer. 2002 Feb;2(2):91-100.

[12] Giancotti FG, Ruoslahti E. Integrin signaling. Science (New York, NY). 1999 Aug 13;285(5430):1028-1032.

[13] Ren B, Yu YP, Tseng GC, Wu C, Chen K, Rao UN, et al. Analysis of integrin alpha7 mutations in prostate cancer, liver cancer, glioblastoma multiforme, and leiomyosarcoma. Journal of the National Cancer Institute. 2007 Jun 6;99(11):868-880.

[14] Desgrosellier JS, Cheresh DA. Integrins in cancer: biological implications and therapeutic opportunities. Nature reviews Cancer. 2010 Jan;10(1):9-22.

[15] Mitchell K, Svenson KB, Longmate WM, Gkirtzimanaki K, Sadej R, Wang X, et al. Suppression of integrin alpha3beta1 in breast cancer cells reduces cyclooxygenase-2 gene expression and inhibits tumorigenesis, invasion, and cross-talk to endothelial cells. Cancer Res. 2010 Aug 1;70(15):6359-6367.

[16] Saito Y, Sekine W, Sano R, Komatsu S, Mizuno H, Katabami K, et al. Potentiation of cell invasion and matrix metalloproteinase production by alpha3beta1 integrin-mediated adhesion of gastric carcinoma cells to laminin-5. Clinical \& experimental metastasis. 2010 Apr;27(4):197-205. 
[17] Tsuji T, Kawada Y, Kai-Murozono M, Komatsu S, Han SA, Takeuchi K, et al. Regulation of melanoma cell migration and invasion by laminin-5 and alpha3beta1 integrin (VLA-3). Clinical \& experimental metastasis. 2002;19(2):127-134.

[18] Pontes-Junior J, Reis ST, Dall'Oglio M, Neves de Oliveira LC, Cury J, Carvalho PA, et al. Evaluation of the expression of integrins and cell adhesion molecules through tissue microarray in lymph node metastases of prostate cancer. J Carcinog. 2009;8:3-9.

[19] Sung V, Stubbs JT, 3rd, Fisher L, Aaron AD, Thompson EW. Bone sialoprotein supports breast cancer cell adhesion proliferation and migration through differential usage of the alpha(v)beta3 and alpha(v)beta5 integrins. Journal of cellular physiology. 1998 Sep;176(3):482-494.

[20] Rolli M, Fransvea E, Pilch J, Saven A, Felding-Habermann B. Activated integrin alphavbeta3 cooperates with metalloproteinase MMP-9 in regulating migration of metastatic breast cancer cells. Proceedings of the National Academy of Sciences of the United States of America. 2003 Aug 5;100(16):9482-9487.

[21] Reinmuth N, Liu W, Ahmad SA, Fan F, Stoeltzing O, Parikh AA, et al. Alphavbeta3 integrin antagonist S247 decreases colon cancer metastasis and angiogenesis and improves survival in mice. Cancer Res. 2003 May 1;63(9):2079-2087.

[22] Gillan L, Matei D, Fishman DA, Gerbin CS, Karlan BY, Chang DD. Periostin secreted by epithelial ovarian carcinoma is a ligand for alpha(V)beta(3) and alpha(V)beta(5) integrins and promotes cell motility. Cancer Res. 2002 Sep 15;62(18):5358-5364.

[23] Ramirez NE, Zhang Z, Madamanchi A, Boyd KL, O'Rear LD, Nashabi A, et al. The alpha(2)beta(1) integrin is a metastasis suppressor in mouse models and human cancer. J Clin Invest. 2011 Jan;121(1):226-237.

[24] Zutter MM, Santoro SA, Staatz WD, Tsung YL. Re-expression of the alpha 2 beta 1 integrin abrogates the malignant phenotype of breast carcinoma cells. Proceedings of the National Academy of Sciences of the United States of America. 1995 Aug 1;92(16): 7411-7415.

[25] Hall CL, Dubyk CW, Riesenberger TA, Shein D, Keller ET, van Golen KL. Type I collagen receptor (alpha2beta1) signaling promotes prostate cancer invasion through RhoC GTPase. Neoplasia. 2008 Aug;10(8):797-803.

[26] Saramaki OR, Porkka KP, Vessella RL, Visakorpi T. Genetic aberrations in prostate cancer by microarray analysis. International journal of cancer Journal international du cancer. 2006 Sep 15;119(6):1322-1329.

[27] van der P, Vloedgraven H, Papapoulos S, Lowick C, Grzesik W, Kerr J, et al. Attachment characteristics and involvement of integrins in adhesion of breast cancer cell lines to extracellular bone matrix components. Laboratory investigation; a journal of technical methods and pathology. 1997 Dec;77(6):665-675. 
[28] Zhang Z, Ramirez NE, Yankeelov TE, Li Z, Ford LE, Qi Y, et al. alpha2beta1 integrin expression in the tumor microenvironment enhances tumor angiogenesis in a tumor cell-specific manner. Blood. 2008 Feb 15;111(4):1980-1988.

[29] Knox JD, Cress AE, Clark V, Manriquez L, Affinito KS, Dalkin BL, et al. Differential expression of extracellular matrix molecules and the alpha 6-integrins in the normal and neoplastic prostate. Am J Pathol. 1994 Jul;145(1):167-174.

[30] Nagle RB, Hao J, Knox JD, Dalkin BL, Clark V, Cress AE. Expression of hemidesmosomal and extracellular matrix proteins by normal and malignant human prostate tissue. Am J Pathol. 1995 Jun;146(6):1498-507.

[31] Collins AT, Habib FK, Maitland NJ, Neal DE. Identification and isolation of human prostate epithelial stem cells based on alpha(2)beta(1)-integrin expression. Journal of cell science. 2001 Nov;114(Pt 21):3865-3872.

[32] Davis TL, Rabinovitz I, Futscher BW, Schnolzer M, Burger F, Liu Y, et al. Identification of a novel structural variant of the alpha 6 integrin. J Biol Chem. $2001 \mathrm{Jul}$ 13;276(28):26099-26106.

[33] Bonkhoff H, Stein U, Remberger K. Differential expression of alpha 6 and alpha 2 very late antigen integrins in the normal, hyperplastic, and neoplastic prostate: simultaneous demonstration of cell surface receptors and their extracellular ligands. Human pathology. 1993 Mar;24(3):243-248.

[34] Van Slambrouck S, Jenkins AR, Romero AE, Steelant WF. Reorganization of the integrin alpha2 subunit controls cell adhesion and cancer cell invasion in prostate cancer. Int J Oncol. 2009 Jun;34(6):1717-1726.

[35] Hall CL, Dai J, van Golen KL, Keller ET, Long MW. Type I collagen receptor (alpha 2 beta 1) signaling promotes the growth of human prostate cancer cells within the bone. Cancer Res. 2006 Sep 1;66(17):8648-8654.

[36] Pontes-Junior J, Reis ST, de Oliveira LC, Sant'anna AC, Dall'oglio MF, Antunes AA, et al. Association between integrin expression and prognosis in localized prostate cancer. Prostate. 2010 Aug;70(11):1189-1195.

[37] Trikha M, Raso E, Cai Y, Fazakas Z, Paku S, Porter AT, et al. Role of alphaII(b)beta3 integrin in prostate cancer metastasis. Prostate. 1998 May 15;35(3):185-192.

[38] Stachurska A, Elbanowski J, Kowalczynska HM. The role of alpha5ss1 and alphavss3 integrins in relation to adhesion and spreading dynamics of prostate cancer cells interacting with fibronectin under in vitro conditions. Cell biology international. 2012 Jun 11:aheadofprint.

[39] Zheng DQ, Woodard AS, Fornaro M, Tallini G, Languino LR. Prostatic carcinoma cell migration via alpha(v)beta3 integrin is modulated by a focal adhesion kinase pathway. Cancer Res. 1999 Apr 1;59(7):1655-1664.

[40] Nemeth JA, Cher ML, Zhou Z, Mullins C, Bhagat S, Trikha M. Inhibition of alpha(v)beta3 integrin reduces angiogenesis, bone turnover, and tumor cell prolifera- 
tion in experimental prostate cancer bone metastases. Clinical \& experimental metastasis. 2003;20(5):413-420.

[41] Nagle RB, Knox JD, Wolf C, Bowden GT, Cress AE. Adhesion molecules, extracellular matrix, and proteases in prostate carcinoma. Journal of cellular biochemistry Supplement. 1994;19:232-237.

[42] Davis TL, Cress AE, Dalkin BL, Nagle RB. Unique expression pattern of the alpha6beta4 integrin and laminin-5 in human prostate carcinoma. Prostate. $2001 \mathrm{Feb}$ 15;46(3):240-248.

[43] King TE, Pawar SC, Majuta L, Sroka IC, Wynn D, Demetriou MC, et al. The role of alpha 6 integrin in prostate cancer migration and bone pain in a novel xenograft model. PLoS One. 2008;3(10):3535-3542.

[44] Tomita K, van Bokhoven A, van Leenders GJ, Ruijter ET, Jansen CF, Bussemakers MJ, et al. Cadherin switching in human prostate cancer progression. Cancer Res. 2000 Jul 1;60(13):3650-3654.

[45] Umbas R, Schalken JA, Aalders TW, Carter BS, Karthaus HF, Schaafsma HE, et al. Expression of the cellular adhesion molecule E-cadherin is reduced or absent in highgrade prostate cancer. Cancer Res. 1992 Sep 15;52(18):5104-5109.

[46] Gould Rothberg BE, Bracken MB. E-cadherin immunohistochemical expression as a prognostic factor in infiltrating ductal carcinoma of the breast: a systematic review and meta-analysis. Breast cancer research and treatment. 2006 Nov;100(2):139-148.

[47] Chan AO, Lam SK, Wong BC, Kwong YL, Rashid A. Gene methylation in non-neoplastic mucosa of gastric cancer: age or Helicobacter pylori related? Am J Pathol. 2003 Jul;163(1):371-373.

[48] Dorudi S, Hanby AM, Poulsom R, Northover J, Hart IR. Level of expression of E-cadherin mRNA in colorectal cancer correlates with clinical outcome. British journal of cancer. 1995 Mar;71(3):614-616.

[49] Batlle E, Sancho E, Franci C, Dominguez D, Monfar M, Baulida J, et al. The transcription factor snail is a repressor of E-cadherin gene expression in epithelial tumour cells. Nature cell biology. 2000 Feb;2(2):84-89.

[50] Cano A, Perez-Moreno MA, Rodrigo I, Locascio A, Blanco MJ, del Barrio MG, et al. The transcription factor snail controls epithelial-mesenchymal transitions by repressing E-cadherin expression. Nature cell biology. 2000 Feb;2(2):76-83.

[51] Peinado H, Portillo F, Cano A. Transcriptional regulation of cadherins during development and carcinogenesis. The International journal of developmental biology. 2004;48(5-6):365-375.

[52] Blobe GC, Schiemann WP, Lodish HF. Role of transforming growth factor beta in human disease. The New England journal of medicine. 2000 May 4;342(18):1350-1358. 
[53] Derynck R, Akhurst RJ, Balmain A. TGF-beta signaling in tumor suppression and cancer progression. Nature genetics. 2001 Oct;29(2):117-129.

[54] Nakao A, Imamura T, Souchelnytskyi S, Kawabata M, Ishisaki A, Oeda E, et al. TGFbeta receptor-mediated signalling through Smad2, Smad3 and Smad4. The EMBO journal. 1997 Sep 1;16(17):5353-5362.

[55] Comijn J, Berx G, Vermassen P, Verschueren K, van Grunsven L, Bruyneel E, et al. The two-handed $\mathrm{E}$ box binding zinc finger protein SIP1 downregulates E-cadherin and induces invasion. Molecular cell. 2001 Jun;7(6):1267-1278.

[56] Postigo AA, Depp JL, Taylor JJ, Kroll KL. Regulation of Smad signaling through a differential recruitment of coactivators and corepressors by ZEB proteins. The EMBO journal. 2003 May 15;22(10):2453-2462.

[57] Verschueren K, Remacle JE, Collart C, Kraft H, Baker BS, Tylzanowski P, et al. SIP1, a novel zinc finger/homeodomain repressor, interacts with Smad proteins and binds to 5'-CACCT sequences in candidate target genes. J Biol Chem. 1999 Jul 16;274(29): 20489-20498.

[58] Miyaki M, Iijima T, Konishi M, Sakai K, Ishii A, Yasuno M, et al. Higher frequency of Smad4 gene mutation in human colorectal cancer with distant metastasis. Oncogene. 1999 May 20;18(20):3098-3103.

[59] Ackland ML, Newgreen DF, Fridman M, Waltham MC, Arvanitis A, Minichiello J, et al. Epidermal growth factor-induced epithelio-mesenchymal transition in human breast carcinoma cells. Laboratory investigation; a journal of technical methods and pathology. 2003 Mar;83(3):435-448.

[60] Koenig A, Mueller C, Hasel C, Adler G, Menke A. Collagen type I induces disruption of E-cadherin-mediated cell-cell contacts and promotes proliferation of pancreatic carcinoma cells. Cancer Res. 2006 May 1;66(9):4662-4671.

[61] Shintani Y, Fukumoto Y, Chaika N, Svoboda R, Wheelock MJ, Johnson KR. Collagen I-mediated up-regulation of $\mathrm{N}$-cadherin requires cooperative signals from integrins and discoidin domain receptor 1. The Journal of cell biology. 2008 Mar 24;180(6): 1277-1289.

[62] Alexander NR, Tran NL, Rekapally H, Summers CE, Glackin C, Heimark RL. N-cadherin gene expression in prostate carcinoma is modulated by integrin-dependent nuclear translocation of Twist1. Cancer Res. 2006 Apr 1;66(7):3365-3369.

[63] Dumont N, Arteaga CL. Transforming growth factor-beta and breast cancer: Tumor promoting effects of transforming growth factor-beta. Breast cancer research : BCR. 2000;2(2):125-132.

[64] Bates RC, Bellovin DI, Brown C, Maynard E, Wu B, Kawakatsu H, et al. Transcriptional activation of integrin beta6 during the epithelial-mesenchymal transition defines a novel prognostic indicator of aggressive colon carcinoma. J Clin Invest. 2005 Feb;115(2):339-347. 
[65] Bhowmick NA, Zent R, Ghiassi M, McDonnell M, Moses HL. Integrin beta 1 signaling is necessary for transforming growth factor-beta activation of p38MAPK and epithelial plasticity. J Biol Chem. 2001 Dec 14;276(50):46707-46713.

[66] Haraguchi M, Okubo T, Miyashita Y, Miyamoto Y, Hayashi M, Crotti TN, et al. Snail regulates cell-matrix adhesion by regulation of the expression of integrins and basement membrane proteins. J Biol Chem. 2008 Aug 29;283(35):23514-23523.

[67] Neal CL, McKeithen D, Odero-Marah VA. Snail negatively regulates cell adhesion to extracellular matrix and integrin expression via the MAPK pathway in prostate cancer cells. Cell Adh Migr. 2011 May-Jun;5(3):249-257.

[68] Drake JM, Barnes JM, Madsen JM, Domann FE, Stipp CS, Henry MD. ZEB1 coordinately regulates laminin-332 and \{beta\}4 integrin expression altering the invasive phenotype of prostate cancer cells. J Biol Chem. 2010 Oct 29;285(44):33940-33948.

[69] Nam EH, Lee Y, Park YK, Lee JW, Kim S. ZEB2 upregulates integrin alpha5 expression through cooperation with Sp1 to induce invasion during epithelial-mesenchymal transition of human cancer cells. Carcinogenesis. 2012 Mar;33(3):563-571.

[70] McNeel DG, Eickhoff J, Lee FT, King DM, Alberti D, Thomas JP, et al. Phase I trial of a monoclonal antibody specific for alphavbeta3 integrin (MEDI-522) in patients with advanced malignancies, including an assessment of effect on tumor perfusion. Clinical cancer research : an official journal of the American Association for Cancer Research. 2005 Nov 1;11(21):7851-7860.

[71] Trikha M, Zhou Z, Nemeth JA, Chen Q, Sharp C, Emmell E, et al. CNTO 95, a fully human monoclonal antibody that inhibits alphav integrins, has antitumor and antiangiogenic activity in vivo. International journal of cancer Journal international du cancer. 2004 Jun 20;110(3):326-335.

[72] Bradley DA, Daignault S, Ryan CJ, Dipaola RS, Cooney KA, Smith DC, et al. Cilengitide (EMD 121974, NSC 707544) in asymptomatic metastatic castration resistant prostate cancer patients: a randomized phase II trial by the prostate cancer clinical trials consortium. Invest New Drugs. 2011 Dec;29(6):1432-1440.

[73] Alva A, Slovin S, Daignault S, Carducci M, Dipaola R, Pienta K, et al. Phase II study of cilengitide (EMD 121974, NSC 707544) in patients with non-metastatic castration resistant prostate cancer, NCI-6735. A study by the DOD/PCF prostate cancer clinical trials consortium. Invest New Drugs. 2012 Apr;30(2):749-757. 